\title{
Gotse Delçev (Nevrokop) Türk ağzında ünlü uyumlarına aykırı gelen tipolojik durumlar
}

\section{Harun BEKIR1}

\begin{abstract}
APA: Bekir, H. (2019). Gotse Delçev (Nevrokop) Türk ağzında ünlü uyumlarına aykırı gelen tipolojik durumlar. RumeliDE Dil ve Edebiyat Araştırmaları Dergisi, (Ö5), 14-22. DOI: 10.29000/rumelide.606060.
\end{abstract}

$\ddot{O} \mathbf{z}$

Türk ağızlarının araştırılması ve incelenmesinde günümüze kadar çeşitli yöntemler uygulanmış ve bu dil varlıkları çeşitli yönlerinden gösterilip tanıtılmıştır. Bulgaristan'daki Türk ağızları yirminci yüzyılın başlangıcından bu yana bilginlerin dikkatini çekmiş ve araştırma konusu olmuştur. Sözkonusu Türk ağızlarının ünlü değişmeleri, bir kısım Anadolu ağızlarında görülebilecek türden olmasına karşılık kendine has özellikleriyle dikkat çekmektedir. Ağız özellikleri yazılı kurallara bağlı değildir. Nevrokop Türk ağızlarında da yazı diline aykırı gelen bazı durumların olması çok normal bir şeydir. Bu yüzden büyük ve küçük ünlü uyumuna uygun sözcük ve sözcük biçimleri olduğu gibi, aykırı gelen tipolojik durumlar da vardır. En tipik özelikleri de ünlü uyumunun çeşitli durumlarda bozulmasıdır.Bu bildirimizde de Nevrokop Türk ağızlarında ünlü uyumlarına aykırı gelen tipolojik durumlara değinmek istiyoruz. Önümüzde duran niyet ve amaçlarımızı gerçekleştirmek için de saha çalışmaları yaptık, malzeme derleyip topladık ve bu sorunlarla ilgili kaynakları ve kitapları bir bir taradık. Söz konusu ağızlarda görülen ünlü uyumsuzluklarının bir kısmı bu bölge ağızları için karakteristik özellik taşırken, bazıları da belirli ses bilgisi özellikleriyle açıklanabilen ve Türkiye Türkçesi ağızlarının genelinde görülen ünlü uyumsuzluklarıdır.

Anahtar kelimeler: Bulgaristan, Nevrokop, Türk ağızları, ünlü uyumların bozulması.

\section{Tipolojic conditions concerning vokal conformites in Gotse Delchev (Nevrokop) Turkish origins}

\begin{abstract}
Various methods have been applied to investigate Turkish dialects, so these local language entities have been shown and presented in various ways. Since the beginning of the twentieth century, Turkish dialects in Bulgaria have attracted the attention of scholars and have been the subject of research. Famous changes in the Turkish dialects can be seen in some Anatolian dialects, drawing attention with their unique features. There are some cases contrary to the written language in Nevrokop Turkish dialects as opposed to written rules in regional dialects. Therefore, there are typological situations that are contrary to words and word forms besides the adaptation of big and small vowels. In other words, the Turkish dialects, we focus on, are the dialects of the Western Balkans, and the most typical features of their famous harmony are that their adaptation is distorted in various situations. In this paper, we would like to mention the typological conditions of the Nevrokop Turkish dialects which are contrary to the famous harmony. In order to realize our intentions and objectives, we conducted field studies, collected materials, scanned the resources and books related to these problems. Some of the mismatch in the aperture opening is specific for this
\end{abstract} oooo-0002-2340-939X [Makale kaylt tarihi: 12.06.2019-kabul tarihi: 18.08.2019; DOI: 10.29000/rumelide.606060] 
area; it explains some of the specific features and voice information mismatches between Turkish dialects.

Keywords: Bulgaria, Nevrokop, Turkish dialects, deterioration of famous harmony.

\section{Giriş}

Bulgaristan'ın güneybatısında Blagoevgrad (Cuma-i Bâlâ) iline bağlı olan ve eski adıyla Nevrokop diye bilinen Gotse Delçev, Mesta (Karasu) vadisinde bulunup Pirin ile Rodop dağlarılla çevrilmektedir. Yunanistan sınırının $22 \mathrm{~km}$ kuzeyinde olan bu kasaba, deniz seviyesinden 508 metre yükseklikte, ve kısmen Akdeniz iklimi etkisi altındadır. 1951 yılında Nevrokop'a Gotse Delçev adı verilmiştir. Gotse Delçev'in güneyinde ve 2212 metre yükseklikte Alibotuş tepesi bulunmaktadır. 1951 yllında bu tepeye Gotsev Vrıh adı verilmiştir. Kasaba yakınlarında, dağ sırtında geçit veren ve Papaz Çayır diye adlandırılan yer bulunmaktadır. Bu yerin en yüksek noktası 1395 metredir. Papaz Çayır, Götse Delçev’in en güzel tatil yerlerinden biridir. Eskiden burada Eflaklı çobanların oturduğu bir köy bulunmaktaymış. Gotse Delçev'in güneydoğusunda küçük bir ova bulunmaktadır. $25 \mathrm{~km}$ uzunlukta ve $10 \mathrm{~km}$ genişlikte olan bu ovanın ortasından Mesta (Karasu) nehri akmaktadır. Ovanın batısında Pirin, güneyinde ise Bozdağ bulunmaktadır. 19. yüzyıla kadar Nevrokop, bayındırlaştırılması ihmal edilen bir kasabayken 20. yüzyılın ikinci yarısından ise gelişip güzelleşmesi, hayat şartlarının uygun duruma getirilmesi için üzerinde çalışılmıştır. Eski dar sokakların hemen hemen hepsi genişletilip düzeltilmiş ve birçok güzel binalar inşa edilip sıralanmıştır. 1926 yılına kadar Nevrokop’un nüfusu 7200 kişiyi aşmamaktadır. Nüfus sayısı 1934 yllında 8767, 1946 yılında 11115, 1956 yılında ise 12526 kişiye ulaşmaktadır. Bulgaristan Milli İstatistik Enstitüsü’nün verilerine göre günümüzde Gotse Delçev’in nüfusu 18353’tür².

Osmanlı döneminde yoğun Türk nüfusu olan bölgede, günümüzde Türkler Gotse Delçev’in doğusunda, Karasu nehrinin karşı yakasında Dıbnitsa, Hvostane ve Blatska köylerinde yaşamaktadır. Dıbnitsa köyü Gotse Delçev'den $9 \mathrm{~km}$ mesafede, Grrmen Belediyesine bağlı bir köydür. Köyün civarında Orta Çağlardan bir kale harabeleri bulunmaktadır. Dıbnitsa'dan $3 \mathrm{~km}$ doğuda ve yine Grrmen Belediyesine bağlı Hvostane köyü bulunmaktadır. Bu köyün adı kaynaklarda 1934 yılına kadar Fustane olarak geçmektedir. Blatska köyü, Dıbnitsa'dan 5 km mesafede, Hacidimovo (Singirti) Belediyesine bağlı bir köydür. Sözü geçen bu köy sakinleri asırlar buyunca geçimini tarımcılıkla sağlamıştır. Bulgaristan Milli İstatistik Enstitüsü’nün 2011 yllındaki nüfus sayımına göre bölgede 2079 Türkçe konuşan kişi belirlenmiştir, ki bunlardan 693 kişi Dıbnitsa, 428 kişi Hvostane, 195 kişi de Blatska köylerinde yaşamaktadır3.

\section{Yöntem}

$\mathrm{Bu}$ bildirimizde Gotse Delçev (Nevrokop) Türk ağzında ünlü uyumlarına aykırı gelen tipolojik durumlara değinmek istiyoruz. Bunun için Bulgaristan Türk ağıları ve genelde Balkan Türk ağızları üzerine yapılmış araştırmalarla ilgili kaynakları ve kitapları bir bir taradıktan sonra bu Türk ağzı üzerine bilimsel çalışmaların olmadığı veya çok sınırlı olduğunu tespit edildi. Dolaysıyla tarama yöntemininin uygulanamayacağı sonucuna vardık. Önümüzde duran niyet ve amaçlarımızı gerçekleştirmek için de saha çalışmaları yaptık ve ses kaydı cihazıyla konuşmalar kaydedilerek metine dönüştürdükten sonra

2 http://www.nsi.bg/bg/content/ (erişim 06.06.2019)

3 https://www.nsi.bg/ (erişim 06.06.2019) 
bu ağız üzerine daha yakından incelemeler yapmaya çalıştık. Ayrıca kendi memleketim olduğu için bu bölgedeki Türk ağzını yakından tanımam araştırmamızda yol gösterici olmuştur.

\section{Gotse Delçev (Nevrokop) Türk ağzının Balkan Türk ağızlarındaki yeri}

Balkanlardaki Türk ağızları yirminci yüzyılın başlarından bu yana bilginlerin dikkatini çekmiş ve araştırılmıştır. Anadolu Türk ağızları gibi Balkan Türk ağızları da bu coğrafyada farklı tarihî, coğrafi, sosyal ve kültürel şartlar altında oluşturulan ağılardır. Bunun yanı sıra Balkan coğrafyasında başta Slavlar olmak üzere farklı dil ve kültürlerle etkileşim içinde bulunma vb. sebeplerle kendi içinde dallanmıştır. Balkan Türk ağızları üzerindeki çalışmaların, Kuzeydoğu Bulgaristan Türk ağızları üzerine yapılan çalışmalarla başlandığını söyleyebiliriz. V. Moşkov, 1903 yılında Balkanlar’ı dolaşır, Kuzeydoğu Bulgaristan'ı da ziyaret eder. Yeni Pazar'ın (Novi Pazar'ın) yakınında bulunan Pamukçu adında bir Türk köyünde çalışmalar yapar ve Pamukçu köyü Türk ağzı ile Besarabya’nın Beşalma köyü Gagavuz ağzını karşlaştırır (Moşkov, 1904).

Balkan Türk ağızlarının ilk incelemeler arasında Ignácz Kúnos’un çalışmalarını da kaydedebiliriz. Ignácz Kúnos, 1906 yllında atasözleri derlemesine dayanan "Rumelisch-türkische Sprichwörter" adlı makalesini yayımlamıştır. Kúnos'un derlemeleri Türk halk edebiyatı açısından olduğu kadar, diyalektoloji açısından da önemli sayılmaktadır (Németh 1981: 113).

Sofya Üniversitesi öğretim üyesi Dimitar Gacanov Bulgaristan Türk ağızları üzerine çalışmalar yapan ilk Bulgar araştırmacıdır. Gacanov, 1910 ve 1911 yıllarında Viyana İlimler Akademisine gönderdiği Kuzeydoğu Bulgaristan Türk ağızlarına ait iki ayrı raporu yayımlar (Olcay 1995: 11; Németh 1981: 115; Günşen, 2012).

Balkan Türk ağızları üzerine ilk yöntemli araştırmacısı Polonyalı Tadeusz Kowalski sayılmaktadır. Kowalski’nin 1931 yllında Encyclopédie de I’slâm için yazdığı "Dialectes turks-osmanlis" adlı ansiklopedi maddesi ile 1933 yılında yayımladığ " "Les Turcs et la langue Turque de la Bulgarie du nordest” adlı Kuzeydoğu Bulgaristan Türklerini ve Türkçelerini konu alan makalesi bu konuda önemli yer almaktadır (Olcay, 1995: 11-12; Németh, 1981: 115; Kowalski, 1933).

Bunlardan da anlaşılacağı gibi araştırılan Türk ağızları, konumuz olan Gotse Delçev bölgesiyle ilgili değildir. 20. yüzyılın ortalarına kadar yapılan incelemeler de bu bölgeden uzak köy ve kentlerinin Türk ağızlarına aittir.

Balkanlardaki Türk ağızlarının sınıflandırılması konusunda birçok araştırmacı fikir yürütmüş olsa da, bu alanda ilk ciddi denemeyi Macar Türkolog Németh yapmıştır. Balkan Türk ağızları üzerinde bilimsel yöntem ve gramerlik ölçütler kullanarak ilk sınıflandırma denemesini yapan Macar Türkolog J. Németh, kendisinden sonra sınıflandırma denemesi yapan araştırmacılar tarafından örnek alınmış, tasnif denemesini temel alarak kendi kriterlerini geliştirmişler ve tasniflerini yapmışlardır. Balkan Türk ağızları açısından Macar Türkolog J. Németh’in araştırmaları önemli bir yer almaktadır. Németh 19271938 yılları arasında Bulgaristan'da Türk ağızları üzerine metinler derlemiş, incelemeler yapmıştır. Németh’in bu konudaki en önemli çalışmalarından biri "Bulgaristan Türk Ağızlarının Sınıflandırılması Üzerine" adlı çalışmasıdır (Németh, 1981).

J. Németh, sekiz esasa dayanarak Balkan Türk ağızlarını Doğu ve Batı olmak üzere iki gruba ayırmıştır. Aralarındaki sınır Lom-Samıkov-Küstendil-Makedonya çizgisini göstermiştir. Gerçeğe çok yakın olan bu bölümlemenin hattı, Bulgar ağızlarının yat izoglosuna isabet eder. Németh, tasnifinde geçiş 
ağızlarından da söz eder. Mesela, Lom'un çok daha doğusundaki Orechovo'da ve Güneybatı Bulgaristan'da Blageovgrad'da, daha ötede Gotse Delçev çevresinde de Batı Rumeli ağızları özelliklerini bulduğunu belirtir (Németh, 1981: 119-120). Böylelikle de Gotse Delçev ve yöresi Türk ağzı en nihayet araştırma konusu olmuş, hakkında da bazı bilgiler verilmiştir. Başta gelenler, üzerinde durduğumuz ağzın Batı Balkan Türk Ağızlarına ait olduğu, en tipik özelliklerinin de ünlü uyumunun çeşitli durumlarda bozulduğudur.

Németh’in öğrencilerinden G. Hazai Türk ağızlarının sınıflandırılmasına değinmiş ve hocasının tasnifini tamamlamaya çalışmıştır. Macar Türkolog G. Hazai, "Anadolu ve Rumeli Ağızlarının Tasnifi Üzerine” adlı çalışmasında, Türk ağızlarının kuramsal olarak fonoloji, morfoloji ve morfofonoloji olmak üzere üç ölçüte dayandırılarak sınıflandırılabileceğini belirtir. Hazai, Doğu Balkan grubu içinde "Doğu Rodoplar Türk diyalektleri” ve "Deliorman diyalektleri”nin mevcudiyetinden söz etmektedir. Bununla birlikte Batı Balkan Türk ağızları arazisi içinde, özellikleri farklı olan Yürük ağızlarını ayırmayı uygun görmüştür (Hazai, 1971: 84-86). Ne yazık ki bu araştırmacı bizim Türk ağzını araştırdığımız bölgeyi ziyaret etmemiş, hakkındaki bilgileri dolaylı yollardan elde etmiştir.

Mollova, Németh’in (1981) tasnifine büyük oranda katılmakla birlikte, onun sınıflandırmasını kendisine göre tamamlamış, Balkan Türk ağızlarını Németh’ten farklı olarak iki değil de, Batı uç zonu, Doğu Rodoplar zonu ve Merkez zon olmak üzere üç ağız bölgesine ayırmıştır (Mollova, 1999).

Mollova'nın (1999) Batı uç zonu olarak verdiği ağız bölgesi, Németh’in Batı Rumeli grubuna yakın olmakla birlikte tamamen örtüşmemektedir. Németh'e göre iki sahayı ayıran çizgi Tuna'nın yanındaki Lom'dan doğuya doğru uzanır, güney yönünde Vraca'dan, Sofya'dan ve Samokov'dan doğuya doğru gider, sonra buradan batıya yönelir ve Köstendil'de yine güneye doğru ilerler, Yunanistan'da Selanik'ten geçerek Ege Denizi'ne ulaşır (Németh 1981: 119; Mollova 1999: 168). Mollova'nın sinırı biraz daha doğudan geçerek Batı uç zonunda Nevrokop, Blagoevgrad (Cuma-i Balâ), Devin kasabaları ve onların etrafındaki köyleri içine alır. Németh’in Batı Rumeli ağızlarını Doğu Rumeli ağızlarından ayıran özellikler olarak gösterdiği sekiz ölçütten ilk altısı Mollova’nın Batı uç zonu için de geçerlidir.

Bulgar Türkolog Emil Boev de Bulgaristan Türk ağızlarının özellikleri, yayılışları ve gruplaşmaları bakımından değişik bir sınıflandırma yapmakta ve bu ağızları üç gruba ayırmaktadır: 1. Batı Bulgaristan Türk ağızları, ki kendi tarafından ikiye ayrılır: Kuzey Batı grubu (Köstendil ağızı dahil olmak üzere) ve Güney Batı grubu (arazisi içinde dağınık bir şekilde bulunan Yürüklerin ağızları); 2. Doğu Bulgaristan ağızları, ki kendi tarafından Mizya ve Trakya grubu olmak üzere iki büyük gruba ayrılır; 3. Doğu Rodoplar Türk ağızları, ki kendi tarafından küçük küçük ağızlara ayrılır4. Bu ağız gruplarının içinde başka başka alt ağız gruplarının da tespit edildiğini belirten Emil Boev'e göre, üç ana ağız grubunun şekillenmesinde Pirin Dağı ile Rodop Dağları arasındaki ağızları, yani Gotse Delçev (Nevrokop) ağızlarını Yürük ağızları olarak tanımlamakta ve özel bir yer aldığını belirtmektedir. Ayrıca 1978 yılında düzenlenen I. Milli Türkoloji Kongresi’nde Emil Boev'in sunduğu "Güneybatı Bulgaristan Türk Ağızlarında Gelecek Zaman” başlıklı bildirisi bu ağızlardaki özel bir duruma değindiği anlaşılmaktadır. Böyle bir bildirinin sunulduğunu Ali Eminov'un5 "Turkish Language/Dialects in Bulgaria/Balkans and Related Materials" derlemesinden ve Cemile Uzun'un "Balkanlarla İlgili Türkiye’de Yapılmış

\footnotetext{
4 Emil Boev’in sınıflandırılması, Sofya Üniversitesi Türkoloji Bölümü’nde kendisi tarafından verilen Diyalektoloji dersindeki ders notlarından alınmıştır.

5 https://www.academia.edu/3292360/Bibliography_Turkish_Language_and_Dialects_in_Bulgaria (erişim 06.06.2019)
}

Adress

Kurklareli University, Faculty of Arts and Sciences, Department of Turkish Language and Literature, Kayalı Campus-Kırklareli/TURKEY e-mail: editor@rumelide.com 
Çalışmalar" adlı makalesinden anlamaktayız (Uzun 2018: 149). Ancak "Birinci Milli Türkoloji Kongresi/Tebliğler”6 (1980) kitabında söz konusu bu çalışma makale olarak yer almamaktadır.

\section{Gotse Delçev (Nevrokop) Türk ağzında ünlü uyumuna aykırı gelen tipolojik durumlar}

Yazı dilindeki ünlülerin kullanımının gelişigüzel olmadığını ve dizilişlerinin çeşitli kurallara bağlanmış olduğunu biliyoruz. Buna göre ses olaylarından büyük ünlü uyumu ve küçük ünlü uyumundan söz edilir. Türkçenin en tipik özelliklerinden olan bu kurallar araştırdığımız bölge ağzında da vardır. Örnek olarak büyük ünlü uyumuna uyan sözcük ve sözcük biçimleri (alma, vakıt, kardaş, yarm, orman, işçiler, inekler, evde) olduğu gibi, küçük ünlü uyumuna uyan sözcük ve sözcük biçimleri (güzel ${ }^{\circ}$, demet, gül ${ }^{\circ} m e k$, demirci, balık, koyruk, inişte, kulak, sıcak) de vardır. Ayrıca Nevrokop Türk ağızlarında yazı diline aykırı gelen bazı durumların olacağı çok normal bir şeydir. Bu yüzden büyük ve küçük ünlü uyumuna uygun sözcük ve sözcük biçimleri olduğu gibi, aykırı gelen tipolojik durumlar da vardır. Başka bir deyişle üzerinde durduğumuz Türk ağızları Batı Balkan Türk ağızlarına (diyalektlerine) ait oldukları ve en tipik özeliklerinin de ünlü uyumunun çeşitli durumlarda bozulmasıdır. Bu çalışmamızda, üzerinde fazla araştırmalar yapılmadığı için hakkında çok az bilgi bulunan Nevrokop Türk ağzının bazı özelliklerini ortaya çıkarmaya çalışacağız.

Yaptığımız incelemeler sonucunda ünlü uyumuna aykırı gelen tipolojik durumları şöyle sıralayabiliriz:

İki veya çok heceli sözcüklerin sonunda /1/, /u/ ve /ü/ ünlüleri bulunmaz. Kök ünlüsü ne olursa olsun, sözcüğün sonunda açık hecedeki ünlü ses uyumuna uymaz ve her zaman /i/'dir: alti, kuzi, ayri, kapi, kuyi, kuti, buri, üti, aci, yazi, turşi, komşi, küpri, saygi vb.

Tek varyantlı bazı eklerde sadece /i/ bulunması ya da kelime sonunda /ü/, /u/ ve /1/'ya karşllı sadece /i/'nin kullanılması Batı Balkan Türkçesinin ağızları için karakteristiktir. Bu durumlarda Türkiye Türkçesinde ünlü uyumunun bulunduğu şekiller standartlaşmıştır. Batı Balkan Türk ağızlarının özelliklerinden bahseden araştırmacılar (Németh 1980-1981; Friedman 2002; Hasan 1997; Eckmann 1960; Günşen 2009) da söz konusu özelliği tespit etmiş ve kelime sonunda dar ünlülerden sadece /i/ vardır demektedirler. Gürer Gülsevin de "Rumeli Türkçesi Çerçevesinde Türk ve Balkan Dillerinin Etkileşimi” adlı makalesinde bu konuya deyinmiş ve bu özelliğin sebebini araştırmıştır. Başka araştırmacıların da konuyla ilgili görüşlerini ve varsımlarını değerlendiren Gürsevin, bu ağızlardaki kelimelerin sonunda sadece /i/'nin bulunmasını Eski Anadolu Türkçesinin saklandığı bir şekli olduğunu öne sürmektedir. Ancak araştırmacılar bu kelimelere çoğul ekinin hangi varyantı getirildiği konusunda bilgi vermemektedir. Araştırdığımız Nevrokop Türk ağzında ilginç bir durumla karşı karşıya gelmekteyiz. Yukarıdaki örnek sözcüklere çoğul eki son hece ünlüsüne göre değil, önceki hece ünlüsüne göre getirilir: altilar, kuzilar, kapilar, avlilar, kuyilar, altilar, kapilar vb.

Ünlü uyumunun bozulduğu kelime köklerinde görüldüğü gibi, onlara getirilen eklerde de görülür. Bu durun hem çekim eklerinde, hem de yapım eklerinde görülmektedir. Gotse Delçev (Nevrokop) Türk ağzında büyük ünlü uyumunda kural dışı aşağıdaki, durumları tespit edilmiştir:

Görülen (belirli) geçmiş zaman ekinin kişi eki almadığı taktirde, yani 3. kişi tekil biçiminde her zaman -di/-ti'li şekil gelir: oynadi, bakti, kapti, aldi, kaçti gibi. Ancak 3. Çoğul şahıs eki getirildiğinde, son hecedeki ünlüye değil de ondan önceki hecelere uyarak kalın olur: oynadilar,baktilar, kaptilar,aldilar. 
Ayrıca aynı örneklerde 1. ile 2. kişi tekil ve çoğul biçimlerinde zaman ekindeki ünlü kalın olur: oynadım, aynadın, oynadık, oynadını, baktım, baktın, baktık, baktını, aldım, aldın, aldık, aldını vb.

Yükleme (belirtme) durumu ekinin de ünlü uyumuna göre varyantları yoktur: kızi, kzzlari, adami, adamnari, koli, kollari, umuzi, umuzlari, burni, burunnari, buni, bunnari vb.

Üçüncü kişi iyelik ekinin ünlü uyumuna göre varyantları yoktur ve her zaman /i/'dir: anasi, odasi, adi, çapasi, analari, kapilari, odalari, adlari, topi vb.

Meslek ve uğraşma ismi yapan $+c i /+c ̧ i$ ekinin ünlü uyumuna göre varyantları yoktur ve her zaman + ci/+çi’dir: sütçi, oyunci, papuççi, almaci, ormanci vb. Ancak son hece dışında diğer hecelerdeki ünlüler kalınsa çoğul eki kalın ünlülü +lar eki getirilir: oyuncilar, paputçilar, almacilar, ormancilar gibi.

+li yapım ekinin de ünlü uyumuna göre varyantları yoktur ve her zaman +li'dir: boyali, köyli, akılli, parali vb. Ancak son hece dışında diğer hecelerdeki ünlüler kalınsa çoğul eki kalın ünlülü +lar eki getirilir: akıllilar, paralilar gibi.

Sıra sayılarını oluşturan ekin de ünlü uyumuna göre varyantları yoktur ve her zaman ekin sonu /i/ ile biter: üçünci, altınci, dokuzunci, onunci vb. Ancak son hece dıșında diğer hecelerdeki ünlüler kalınsa çoğul eki kalın ünlülü +lar eki getirilir: altıncilar, dokuzuncilar, onuncilar.

İlk hece dışında kelime içinde ve son kapalı hecede /i/ sesinin yerine /1/ esi kullanılır: senın, bizım, sizın, isterım, verır, biçerım, ekerım, işimıs, işinıs. Ancak bu sözcük biçimlerine başka bir ek getirildiğinde eklerdeki ünlü ince olur: yerıne, yerınde, bizımnen, verırdi, işimızden vb. Son kapalı hecedeki ünlünün her zaman kapalı olması aşağıdaki sözcük biçimlerinde de ortaya çıkmaktadır:

İlgi (tamlayan) durumu ekinde ünlü her zaman kalın olur: bāçenın, kapinın, gelinın, sürinın, tütünun, gözlerinın/gözlernın vb.

+lIkyapım ekindeki ünlü de her zaman kalın olup -lık ve -luk'tur: kapillk, eşeklık, tütünnuk gibi. Ancak önceki hecelerde ünlü inceyse -lık/-luk ekinden sonra gelen eklerdeki ünlüler de ince olur: eşeklkkler, eşeklıkte, eşeklıkten, tütünnukler, tütünnukte, tütünnukten gibi.

Eylemlerin farklı çatılarında :

çekıl-mek gezın-mek verll-mek,

girdır-mek kestır-mek çektır-mek

içır-mek geçır-mek pişır-mek

Eylemlerde geniş/şimdiki zaman eklerinde: verır, bilır, g'atırır, biçerım, biçersın vb.

Bilindiği gibi Türkçede eylem işletimi sırasında belli bir döneme kadar müstakil bir şimdiki zaman eki görülmemektedir. Eski Türkçe devresinden başlayarak takip edebildiğimiz metinlerde geniş zaman ve şimdiki zaman kavramını Orta Türkçe devresine kadar Türkiye Türkçesinde geniş zaman eki olarak kullandığımız - $r$, -Ar, -Ir biçimbirimleri karşılamıştır (Şahin 2006: 214). Gotse Delçev (Nevrokop) Türk ağzında şimdiki zamanın kullanıldığı, ancak bu zaman kavramının bugün geniş zaman ekleri olarak bildiğimiz eklerle ifade edildiğini söyleyebiliriz. Fakat bu zaman çekiminde 1. kişi çoğul eki yazı dilindekinin farklıdır:
biçersık ( biçeriz)
geçersık (geçeriz)
gidersık (gideriz)
açarsık (açarı) 
Görülen (belirli) geçmiş zaman eylemleri 1 . ve 2. tekil ve çoğu kişi ekleri aldığında i > 1 olur. Örnek olarak ilginç bir sözcükte yani "acele etmek" anlamında kullanılar “evetlemek" sözcüğünde görebiliriz: evetledim evetledik,

evetledin evetledinıs

evetledi evetlediler

Ünlü uyumunun bozulduğu bir diğer tipolojik durum da eylemlerin olumsuzluk biçimlerindedir. Olumsuzluk eki, geniş/şimdiki zaman dışında, tek varyantlıdır ve her zaman -ma'dır: işlemadi, işlemamiş, işlemaycak, işlemasam v.s.

$$
\begin{array}{ll}
\text { girmadim } & \text { girmadik } \\
\text { girmadin } & \text { girmadınz } \\
\text { girmadi } & \text { girmadilar }
\end{array}
$$

Görülmeyen (belirsiz) geçmiş zaman ekinin de ünlü uyumuna göre varyantları yoktur ve her zaman miş’tir: almiş, oynamiş, yapmiş, bakmiş, bulmiş, durmiş, atmiş, takmiş vb.

Batı Balkan Türk ağızlarını inceleyen araştırmacılar da bu ekin tek varyantlı olduğunu ve sadece -miş şekliyle kullandığını tespit etmişlerdir (Ahmed 2006: 32). Yazı dilinde ise ünlü uyumuna giren bu ekin 4 varyantı vardır: -mış, -miş, -muş, -müş. Aslında bu ekin tek varyantlı -miş olduğunu sadece Batı Balkan Türk ağızlarında değil, Türkiye Türkçesi ağızlarının Doğu grubu ile Kuzeydoğu grubunda da tek varyantlı olarak kullanıldığı tespit edilmiştir. Leyla Karahan, Kuzeydoğu grubu ağızlarının özellikleri arasında saydığı bu ekin tek şekilli olmasının Doğu grubu ağızlarına göre daha sistemli olduğunu söyler (Karahan 1996: 47). Metin Karaörs de Kuzeydoğu Anadolu (Trabzon ve yöresi) ağızları ile Batı Rumeli ă̆ızları arasında kıyaslama yapıp bu ağızların ortaklığından ve akrabalıklarından bile bahsetmektedir (Karaörs 2000: 97). Gürer Gülsevin ise “-mIş ekinin eskiden 4 varyantlı iken bazı ağızlarda ünlü uyumu bozularak tek varyantlı hâle mi geldiği, yoksa eskiden tek varyantlı iken birçok ağızda ünlü uyumuna girerek 4 varyantlı mı olduğu" sorusunun cevabı aramakta ve "Eski Türkçe döneminde de Orta Türkçe döneminde de bu ek ünlü uyumuna uymamaktadır. Yani 4 varyantlı olması daha sonra gerçekleşmiştir. Tek varyantlı olan -mişs şekli daha eskidir." sonuca varmaktadır (Gülsevin 2015: 7). Ayrıca Gülsevin bu ekin "bazı Anadolu ağızları ile Batı Rumeli ağızlarında tek şekilli olması da, Köktürkçe metinleri anlamamıza yardımcı olmakta" ve "bu bilgi, tarihî ağızlar açısından bizi şu doğruya götürür: XVII. yüzyıl Batı Rumeli Türkçesi ağızlarında geçmiş zaman eki tek varyantlı olarak miş şeklinde kullanılmaktaydı” diyor (Gülsevin 2015: 8). Dolaysıyla Gotse Delçev (Nevrokop) Türk ağzında bu ekin tek varyantlı -miş olması eski şeklini korumasından kaynaklandığını kesin olarak söyleyebiliriz. Ancak yukarıda kaydettiğimiz diğer örneklerde de olduğu gibi, -miş ekinden önceki hece ünlüsü kalınsa çoğul eki kalın ünlülü +lar eki getirilir: atmişlar, bakmişlar, oynamişlar, yapmişlar, bulmişlar, durmişlar, takmişlar gibi.

Ünlü uyumuna göre varyantı olmadğını tespit ettiğimiz bir diğer ek de şart kipi ekidir ve bu ek her zaman -se'dir: oynarse, bakarse, yaparse, tutarse, atarse, olurse gibi.

Vasıta (araç) durumu ekinin de ünlü uyumuna göre varyantları yoktur ve her zaman + ilen $>+y$ ) len şeklindedir: kızlen, çantaylen, arabaylen, onunnen.

Bilindiği gibi vasıta hâli eki “+n”, Eski Türkçe, Orta Türkçe ve Eski Anadolu Türkçesi dönemlerinde kullanıldıktan sonra, Osmanlıca döneminde kullanımdan düşmüştür. Eski Anadolu Türkçesinde asıl vasıta hâli eki “+n” olmakla birlikte, “+la”, "birle”, "ile” şekilleri de kullanılmıştır. Ancak araştırdığımız bölge ağzında "+n" eki kullanımdan düşmemiş +ilen > +(y)len şeklinde korunmuş ve bir vasıta (araç) 
durumu eki haline gelmiştir. Araştırdığımız bölge ağzında bu ek halâ kullanılmaktadır: çantasiylen, kazmasiylen, koliylen, arabaylen vb.

Ancak 1. ve 2. kişi iyelik çekim ekini almış sözcüklerde bir gerileyici ünsüz benzeşmesi meydana gelip $m l$ - ve -nl- ses grubu -mn- ve -nn- şeklini almaktadır (-ml>-mn-, -nl>-nn-): elınnen, kolunnen, babamnen, babannen, anamnen, anannen $v$.s.

Ünlü uyumuna göre varyantı olmadğını tespit ettiğimiz bir diğer ek de /mi/ soru edatıdır: Gidelım mi? Kalkalım mi? Yapar mi? Bakar misin?

\section{Sonuç}

Söz konusu Türk ağzında görülen ünlü uyumsuzluklarının bir kısmı bu bölge ağızları için karakteristik özellik taşırken, bazıları da belirli ses bilgisi özellikleriyle açıklanabilen ve Türkiye Türkçesi ağızlarının genelinde görülen ünlü uyumsuzluklarıdır. Gotse Delçev (Nevrokop) Türk ağzındaki ünlü değişmeleri, bir kısım Anadolu ağızlarında görülebilecek türden olmasına karşın kendine has özellikleriyle dikkat çekmektedir. Gotse Delçev (Nevrokop) Türk ağzında yazı diline aykırı gelen bazı durumların olacağı çok normal bir şeydir. Bu yüzden büyük ve küçük ünlü uyumuna uygun sözcük ve sözcük biçimleri olduğu gibi, aykırı gelen tipolojik durumlar da vardır. Başka bir deyişle üzerinde durduğumuz Türk ağzı Batı Balkan Türk ağızlarına (diyalektlerine) ait olduğu ve en tipik özelliğinin de çeşitli durumlarda yazı dilindeki ünlü uyumuna aykırı gelen durumların var olduğudur.

Gotse Delçev (Nevrokop) Türkçesinin ayırıcı özelliklerinden bazıları kendi bünyesinde geçirdiği olağan gelişmelerden kaynaklandığı ya da dilin arkaik özelliklerin saklanması sonucu ortaya çıkan özelliklerdir. Başka bir değişle, diğer Batı Balkan Türk ağızlarında da görüldüğü gibi, Gotse Delçev (Nevrokop) Türkçesinde -miş ekinin tek varyantlılığı; çok heceli kelimelerde dar ünlülerden sadece /i/'nin bulunması; şimdiki zaman çekiminde $-r,-A r,-I r$ 'ın kullanılması gibi özelliklerin var olması Eski Anadolu Türkçesinin özelliklerinin korunmuş olmasını göstermektedir. Ayrıca bu özellikleriyle yaşayan Türkiye Türkçesi ağızlarından "Kuzeydoğu Anadolu" ve "Doğu Anadolu" bölgeleri ile paralellik göstermektedir.

\section{Kaynakça}

Ahmed, O. (2006): Makedonya’nın Ohri-Prespa Yöresinde Konuşulan Türk Ağızlarında Eklerin Varyantları, I. Uluslararası Türk Dünyası Kültür Kurultayı, İzmir 20106, Bildiriler I, s. 31-42.

Eckmann (1960): János Eckmann, Dinler (Makedonya) Ağzı, Türk Dili Araştırmaları Yıllı̆̆ı Belleten 1960, TDK Yayınları Ankara 1960, s.189-204.

Friedmann (2002): Victor A. Friedman. Makedonya ve Civar Bölgelerde Balkan Türkçesi, Türkler Ansiklopedisi Cilt 20, Yeni Türkiye Yayınları, Ankara 2002, s.455-463

Gülsevin, G. (2015): Arkaik-Periferik Kavramı ve Bu Kavramın Tarihî Batı Rumeli Türkçesi Ağızlarının Tespitindeki Önemi, International Journal of Social Science, Doi number: http://dx.doi.org/10.9761/JASSS2771, Number: 32 , p. 1-12, Winter III 2015.

Günşen, A. (2009): Dil Etkileşimi Açısından Makedonya ve Kosova Türk Ağızları, Turkish Studies, Volume 4/8, Fall 2009, s. 225-254.

Günşen, A. (2012): Balkan Türk Ağızlarının Tasnifi Üzerine Bir Değerlendirme, International Periodical For The Languages, Literature and History of Turkish or Turkic Volume 7/4, Fall 2012, p. 111129, Ankara, s.111-129.

Hasan (1997): Hamdi Hasan, Makedonya ve Kosova Türklerince Kullanılan Atasözleri ve Deyimler, Türk Dil Kurumu Yayınları, Ankara 1997. 
Hazai, G. (1971): Anadolu ve Rumeli Ağızlarının Tasnifi Üzerine, Voprosi Tyurkologi, haz.: M. Ş. Şiralieva-K. Şestidesyatiletiyo Baku: Akademika AN Azerbaycan SSR, s. 84-86.

Karahan, L. (1996): Anadolu Ağızlarının Sınıflandırılması, Türk Dil Kurumu, Ankara 1996.

Karaörs, M. (2000): Kuzeydoğu Anadolu (Trabzon ve Yöresi) ve Batı Rumeli Türk Ağızlarının Ortaklığı ve Akrabalığı, Trabzon Tarihi Sempozyumu Bildirileri, Trabzon 2000, s. 89-98.

Kowalski, T. (1933): Les Turcs Et La Langue Turque De La Bulgarie Du Nord-est,

Kowalski, T. (1934): Osmanisch-Turkische Dialekte, Enzyklopädie des Islam, IV (S, Z), Leipzig: Leiden, S. 991-1011.

Mollova, M. (1999): Balkanlarda Türk Ağızlarının Tasnifi, TDAY, Belleten 1996, Ankara: TDK, 167-176.

Moşkov, V. (1904): Мошков, В. А., Турецкие племена на Балканском полуострове (Отчет о поездке на Балканский полуостров летом 1903 г.), Известия русского географического общество, T. ХІ., СПб, 1904, 426-436.

Németh, G. (1981-1982): Gyula Németh, Bulgaristan Türk Ağızlarının Sinıflandırılması Üzerine, Türk Dili Araş̧ırmaları Yıllığı Belleten 1981-1982, Türk Dil Kurumu Yayınları, Ankara 1981, s. 113-167.

Olcay, S. (1995): Doğu Trakya Yerli Ağzı, Ankara: TDK.

Şahin, H. (2006): Türkçede Şimdiki Zaman Eklerinin Zaman Belirleyicilerle Kullanımı, Uludă̆ Üniversitesi Fen-Edebiyat Fakültesi Sosyal Bilimler Dergisi, Yll: 7, Sayı: 11, 2006/2, s. 213-221.

Uzun, C. (2018): Balkanlarla İlgili Türkiye'de Yapılmış Çalışmalar, Uluslararası Türk Kültürü ve Dili Sempozyumu Bildirileri, Üsküp, 2018. (http://ukdasempozyum.com/ukda_tam_metin_kitab\%C4\%B1.pdf) (erişim 06.06.2019) 